\title{
KONSEP DISTRIBUSI KEPEMILIKAN DALAM ISLAM
}

\author{
Amir Salim \\ Sekolah Tinggi Ekonomi dan Bisnis Syariah (STEBIS) Indo Global Mandiri \\ Email: amirsalim@ stebisigm.ac.id
}

\begin{abstract}
The background of this research is that God tells humanity to make their contribution to people in need. Wealth that must be managed and distributed to the community and wealth should not only be concentrated in certain groups. Wealth that is only centered on certain groups will hamper economic growth because this cannot be utilized as well as possible and eventually cause community opposition. According to the Islamic economic system, distribution is obtained through data sources obtained from Islamic economic system books, literature, and relevant study materials. Ownership in the concept of Islam, what is in the universe belongs only to Allah. Humans as a trusted caliph to be approved by the universe.
\end{abstract}

Keywords : Distribution, wealth

\section{DASAR PEMIKIRAN}

Kata distribusi disinonimkan dengan kata dulah dalam bahasa Arab. Secara etimologi kata dulah berarti terus berputar atau perpindahan sesuatu dari satu tempat ke tempat lain. Sedangkan secara terminologi kata dulah berarti suatu proses perputaran atau peredaran yang bersifat konstan tanpa ada hambatan.( Zaki Fuad Chalil, 2009: 46 ) Distribusi berarti penyaluran, pembagian, pengiriman barang dagangan atau barang dan jasa kepada konsumen oleh produsen dan pemerintah ( Zaki Fuad Chalil, 2009: 46 )

Pemahaman distribusi juga telah tercantum di dalam Al-Qur'an Surat Al-Hasyr ayat 7 :

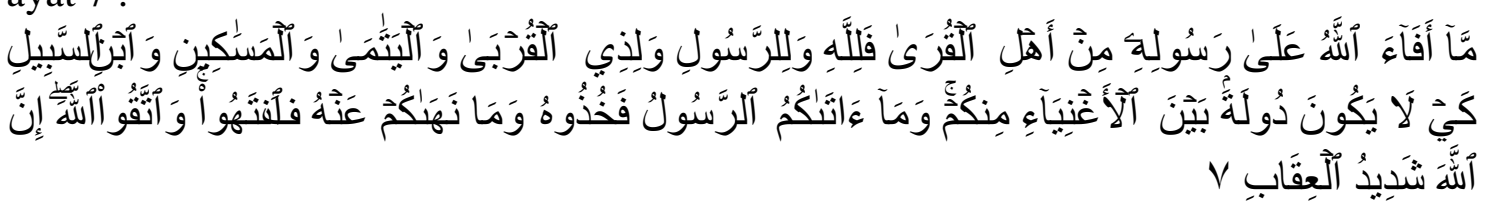

Artinya :

"Apa saja harta rampasan (fai-i) yang diberikan Allah kepada RasulNya (dari harta benda) yang berasal dari penduduk kota-kota Maka adalah untuk Allah, untuk rasul, kaum kerabat, anak-anak yatim, orang-orang miskin dan orang-orang yang dalam perjalanan, supaya harta itu jangan beredar di antara orang-orang Kaya saja di antara 
86 | Amir Salim Konsep Distribusi Kepemilikan Dalam Islam.....

kamu. apa yang diberikan Rasul kepadamu, Maka terimalah. dan apa yang dilarangnya bagimu, Maka tinggalkanlah. dan bertakwalah kepada Allah. Sesungguhnya Allah Amat keras hukumannya."

Berdasarkan ayat diatas, bahwa Allah menyuruh umat manusia untuk mendistribusikan kekayaan mereka secara merata kepada orang-orang yang membutuhkan. Kekayaan yang ada harus dikelola dan dibagi-bagikan kepada seluruh masyarakat dan tidak boleh kekayaan itu hanya terkonsentrasi peredarannya pada kelompok-kelompok tertentu saja( Zaki Fuad Chalil,2009: 50 ). Kekayaan yang hanya berpusat pada sekelompok tertentu akan menghambat pertumbuhan ekonomi karena kekayaan tersebut tidak dimanfaatkan dengan sebaik mungkin dan akhirnya menimbulkan kesenjangan dan ketidakadilan masyarakat.

\section{PEMBAHASAN}

Menurut Yusuf Qardhawi salah satu masalah utama dalam kehidupan sosial dalam masyarakat adalah mengenai masalah distribusi. Harta yang dimiliki harus didistribusikan dengan jalan yang benar. Kepemilikan sumber-sumber kekayaan menjadi titik awal dalam ekonomi Islam adalah masalah distribusi.( Jaribah bin Ahmad Al-Haritsi, 2006: 211 )

\section{Instrumen Distribusi}

Seorang pemilik harta kekayaan mempunyai keinginan untuk memberikan sebagian hartanya kepada pihak lain yang membutuhkan dengan cara dan tujuan tertentu. Adapun instrumen distribusi kekayaan sebagai berikut :

a. Zakat

Secara istilah fiqh, zakat adalah kadar harta tertenu yang diwajibkan Allah untuk diberikan kepada orang-orang yang berhak menerimanya.( Yusuf Qardawi, 1996: 34 ) Zakat merupakan salah satu ibadah yang memiliki dua fungsi, yaitu ibadah secara induvidu dan sosial. Zakat didistribusikan kepada delapan golongan yang berhak menerimanya yaitu fakir, miskin, amil, muallaf, hamba sahaya, orang yang berhutang, orang yang berjuang di jalan Allah, dan orang yang sedang melakukan perjalanan jauh. Harta yang dikeluarkan zakatnya menjadi berkah, tumbuh, berkembang dan bertambah, suci, dan baik ( Abdul Ghofur Anshori, 2006: 113 ). 


\section{b. Sedekah atau Infak}

Sedekah atau infaq adalah memberikan sesuatu tanpa mengharapkan balasan dari manusia dan hanya mengharapkan ganjaran dari Allah SWT.( Abdul Ghofur Anshori, 2018:06 ) Distribusi sedekah atau infaq pada dasarnya sama dengan distribusi zakat yaitu menyangkut delapan golongan di atas, namun sedekah lebih diprioritaskan kepada kalangan yang lebih membutuhkan dan kalangan yang lebih dekat kepada allah.

\section{c. Wakaf}

Wakaf adalah suatu pemberian yang digunakan untuk kepentingan-kepentingan umum yang dibenarkan atau dianjurkan oleh syari’at.( Ali Yafie, 1995:174 ).

\section{d. Nafkah}

Nafkah adalah pemberian yang digunakan untuk membiayai kebutuhan istri, anakanak, dan keluarga dekat yang lemah. Dalam Islam, seorang iman juga dianggap sebagai seorang ayah dalam sebuah keluarga. Artinya, tugas iman atau negara tidak sebatas melindungi hak milik dan melindungi dari berbagai ancaman. Negara juga bertugas menyediakan dan memenuhi kebutuhan rakyatnya terutama rakyat miskin.. ( Yusuf Qardhawi,1995: 143 ).

\section{e. Wasiat}

Wasiat adalah pemberian sejumlah harta sseorang yang diperuntukan bagi orangorang tertentu yang bukan merupakan ahli waris yang akan diterima apabila yang memiliki harta tersebut tela meninggal dunia.( Ali Yafie, 1995:174 )

\section{f. Ghanimah}

Ghanimah adalah harta rampasan perang adalah hal biasa dalam sebuah peperangan ada yang menang dan ada yang kalah.( Asep Subhi dan Ahmad Taufik, 2004: 137 ) Ghanimah diperuntukan seperlimanya untuk Allah, Rasul, kerabat, anak-anak yatim, orang-orang miskin, dan Ibnu Sabil, jika kamu beriman kepada Allah dan kepada apa yang kami turunkan kepada hamba kami pada hari furqan yaitu hari bertemunya dua pasukan.( Muhammad Nasib Ar-Rifa'i, 1999: 524 ) 
88 | Amir Salim Konsep Distribusi Kepemilikan Dalam Islam.....

g. Fa'i

Fa'i adalah harta yang diperoleh dari kaum kafir bukan dengan cara demikian seperti harta sebagai sarana berdamai, harta yang ditinggalkan mati tanpa ada ahli warisnya, jizyah, pajak, dan sebagainya.( Muhammad Nasib Ar-Rifa'I, 1999: 524 ) .

\section{Prinsip-Prinsip Distribusi Dalam Ekonomi Islam}

Distribusi harta kekayaan yang merata dapat mewujudkan perekonomian yang baik. Konsep perencanaan dan pengelolaan sistem distribusi akan berjalan dengan baik, apabila memperhatikan prinsip-prinsip distribusi dalam melaksanakannya. Adapun prinsip-prinsip distribusi dalam ekonomi islam sebagai berikut : ( Idri, Hadis Ekonomi, 2017: 150 ).

a. Prinsip Keadilan dan Pemerataan

Keadilan dalam distribusi sebagai suatu kebebasan melakukan aktivitas ekonomi yang berada dalam bingkai etika dan norma-norma Islam. Prinsip keadilan dan pemerataan dalam distribusi mengandung makna. Pertama, kekayaan tidak boleh dipusatkan pada sekelompok orang saja, tetapi harus menyebar kepada seluruh masyarakat. Kedua, hasil-hasil produksi yang besumber dari kekayaan nasional harus dibagi secara adil. Ketiga, Islam tidak mengizinkan tumbuhnya harta kekayaan yang melampaui batas-batas yang wajar apalagi jika diperoleh dengan cara yang tidak benar.

b. Prinsip Persaudaraan dan Kasih Sayang

Persaudaraan dan kasih sayang akan memperkuat persatuan dan kesatuan umat Islam yang kadang-kadang mendapatkan hambatan dan rintangan sehingga mereka dapat saja terpecah belah dan saling bermusuhan. Prinsip persaudaraan dan kasih sayang tersebut tidak berarti bahwa umat Islam tidak boleh melakukan aktivitas ekonomi dengan non Muslim. Islam memperbolehkan umatnya bertransaksi dengan siapa pun asalkan sejalan dengan prinsip-prinsip transaksi Islam tanpa membedakan agama, ras, dan bangsa. Islam menganjurkan persaudaraan dan kasih sayang dalam distribusi agar supaya umat Islam menjadi kuat, baik secara ekonomi, sosial, politik, budaya, dan sebagainya. 


\section{c. Prinsip Solidaritas Sosial}

Prinsip solidaritas sosial merupakan salah satu prinsip pokok dalam distribusi harta kekayaan. Islam menghimbau adanya solidaritas sosia dan menggariskan dan menentukannya dalam suatu sistem tersendiri seperti zakat, sedekah, dan lain-lain. Prinsip solidaritas sosial dalam ekonomi Islam mengandung beberapa elemen dasar, yaitu : (a) sumber daya alam harus dinikmati oleh semua makhluk Allah, (b) adanya perhatian terhadap fakir miskin terutama oleh orang-orang kaya, (c) kekayaan tidak boleh dinikmati dan hanya beredar di kalangan orang-orang kaya saja, (d) adanya perintah Allah untuk berbuat baik kepada orang lain, (e) umat Islam yang tidak punya kekayaan dapat menyumbangkan tenaganya untuk kegiatan sosial, (f) larangan berbuat baik karena ingin dipuji orang, (g) larangan memberikan bantuan yang disertai dengan perilaku menyakiti, (h) distribusi zakat harus diberikan kepada orang-orang yang telah disebutkan dalam Al-Qur'an sebagai pihak yang berhak menerimanya, (i) anjuran untuk mendahulukan distribusi harta kepada orang-orang yang menjadi tanggungan kemudian kepada masyarakat, (j) anjuran agar distribusi disertai dengan doa agar tercapai ketenangan batin dan kestabilan ekonomi masyarakat, dan (k) larangan berlebihan (boros) dalam distribusi ekonomi di kalangan masyarakat.

\section{SIMPULAN}

Islam memandang bahwa kepemilikan yang ada di muka bumi ini sepenuhnya hanya milik Allah. Kedaulatan yang penuh terhadap ciptaan-Nya di bumi. Manusia sebagai khalifah dipercaya untuk menjaga alam semesta. Jelas tidak seorang pun yang beriman kepada Allah dengan membawa tanggung jawab akan perbuatannya yang telah dilakukan. Manusia diberi kebebasan untuk memiliki harta, berlomba mendapatkannya, dan membelanjakannya. Kepemilikan harta yang ada pada dirinya, harus dipertanggungjawabkan dengan sebaik-baiknya. 
90 | Amir Salim Konsep Distribusi Kepemilikan Dalam Islam.....

\section{DAFTAR PUSTAKA}

Al-Haritsi, Jaribah bin Ahmad dkk. 2006. Fikih Ekonomi Umar bin Al-Khathab. Diterjemahkn oleh : Asmuni Solihan Zamakhsyari. Jakarta : Khalifa.

An-Nabhan, M. Faruq. 2000. Sistem Ekonomi Islam. Yogyakarta : UII Press.

Anshori, Abdul Ghofur, 2018. Filsafat Hukum Hibah dan Wasiat di Indonesia. Yogyakarta : Gadjah Mada University Press.

Anshori, Abdul Ghofur. 2006. Hukum dan Pemberdayaan Zakat, Upaya Sinergis Wajib Zakat dan Pajak di Indonesia, cet. Ke-1. Yogyakarta : Pilar Media.

Ar-Rifa'i, Muhammad Nasib. 1999. Kemudahan dari Allah : Ringkasan Tafsir Ibnu Katsir. Jakarta : Gema Insani Press.

Chalil, Zaki Fuad. 2009. Pemerataan Disribusi Kekayaan Dalam Ekonomi Islam. Jakarta : Erlangga.

Chamid, Nur. 2010. Jejak Langkah Pemikiran Ekonomi Islam. Yogyakarta : Pustaka Belajar.

Idri. 2017. Hadis Ekonomi ; Ekonomi dalam Perspektif Hadis Nabi. Jakarta : Kencana.

Qardawi, Yusuf. 1996. Hukum Zakat. Diterjemahkan oleh : Salman Harun. Bogor : Pustaka Litera Antar Nusa.

Qardhawi, Yusuf. 1997. Norma dan Etika Ekonomi Islam. Diterjemahkan oleh :

Qodratilah, Meity Taqdir. 2011. Kamus Bahasa Indonesia Untuk Pelajar. Jakarta : Badan Pengembangan dan Pembinaan Bahasa.

Rahman, Afzlul. 1997. Muhammad Sebagai Pedagang. Jakarta : Yayasan Shuarna Bhumy.

Yafie, Ali. 1995. Menggagas Fiqih Sosial : Dari Soal Lingkungan Hidup, Asuransi, Hingga Ukhuwah. Bandung : Mizan.

Zainal Arifin LC, Dahlia Husin. Jakarta : Gema Insani Press. 